\title{
CRISPR/Cas9-mediated hypoxia inducible factor-1 $\alpha$ knockout enhances the antitumor effect of transarterial embolization in hepatocellular carcinoma
}

\author{
QUAN LIU ${ }^{1,2^{*}}$, DAHUA FAN ${ }^{3 *}$, DICKSON ADAH ${ }^{4,5^{*}}$, ZHENGZHI WU $^{3}$, RENYAN LIU ${ }^{6}$, QIAO-TING YAN $^{1}$, \\ YUE ZHANG ${ }^{1}$, ZHI-YONG DU ${ }^{1}$, DOU WANG ${ }^{1,2}$, YAN LI ${ }^{1}$, SHI-YUN BAO ${ }^{1}$ and LI-PING LIU ${ }^{1}$ \\ ${ }^{1}$ Department of Hepatobiliary and Pancreas Surgery, Shenzhen People's Hospital, The Second Clinical Medical College of \\ Jinan University, Shenzhen, Guangdong 518020; ${ }^{2}$ Integrated Chinese and Western Medicine Postdoctoral Research Station, \\ Jinan University, Guangzhou, Guangdong 510632; ${ }^{3}$ Department of Chinese and Western Integrative Medicine, \\ The Eighth Affiliated Hospital of Sun Yat-Sen University, Shenzhen, Guangdong 518033; \\ ${ }^{4}$ University of Chinese Academy of Sciences, Beijing 100049; ${ }^{5}$ State Key Laboratory of Respiratory Disease, \\ Department of Infection and Immunity, Guangzhou Institutes of Biomedicine and Health, \\ Chinese Academy of Sciences, Guangzhou, Guangdong 510530, P.R. China; \\ ${ }^{6}$ Department of Pharmacology, Upstate Medical University, State University of New York, \\ Syracuse, NY 13210, USA
}

Received January 19, 2018; Accepted July 31, 2018

DOI: $10.3892 /$ or.2018.6667

\begin{abstract}
Transarterial embolization (TAE) is a palliative option commonly used for the treatment of advanced, unresectable hepatocellular carcinoma (HCC). However, patient prognosis in regards to overall survival has not improved with this method, mainly due to hypoxia-inducible factor- $1 \alpha$ (HIF-1 $\alpha$ )-induced angiogenesis and invasiveness. Thus, it is hypothesized that $H I F-1 \alpha$ may be an ideal knockout target for the treatment of HCC in combination with TAE. Thus, in the present study, $H I F-1 \alpha$ knockout was conducted in human liver cancer SMMC-7721 cells and a xenograft HCC model was established using a lentivirus-mediated CRISPR/Cas system (LV-Cas) with small guide RNA-721 (LV-H721). Furthermore, hepatic artery ligation (HAL) was used to mimic human transarterial chemoembolization in mice. The results revealed
\end{abstract}

Correspondence to: Dr Li-Ping Liu or Dr Shi-Yun Bao, Department of Hepatobiliary and Pancreas Surgery, Shenzhen People's Hospital, The Second Clinical Medical College of Jinan University, 1017 Dongmen North Road, Shenzhen, Guangdong 518020, P.R. China

E-mail: leoliping@aliyun.com

E-mail: baomi94@163.com

*Contributed equally

Abbreviations: HCC, hepatocellular carcinoma; TAE, transarterial embolization; TACE, transarterial chemoembolization; HIF-1 $\alpha$, hypoxia inducible factor- $1 \alpha$

Key words: hepatocellular carcinoma, hypoxia-inducible factor-1 $\alpha$, transarterial embolization, lentivirus, CRISPR/Cas9 that HIF-1 $\alpha$ was highly expressed in both HCC patient tissues and SMMC-7721-induced tumor tissues. The HIF-1 $\alpha$ knockout in SMMC-7721 cells significantly suppressed cell invasiveness and migration, and induced cell apoptosis under $\mathrm{CoCl}_{2}$-mimicking hypoxic conditions. Compared with the control groups, HAL+LV-H721 inhibited SMMC-7721 tumor growth in orthotopic HCC and markedly prolonged the survival of HCC-bearing mice, which was accompanied by a lower CD31 expression (tumor angiogenesis) and increased apoptosis in the tumor cells. These findings demonstrated a valuable antitumor synergism in combining CRISPR/Cas9-mediated $H I F-1 \alpha$ knockout with TAE in mice and highlighted the possibility that HIF-1 $\alpha$ may be an effective therapeutic knockout target in combination with TAE for HCC treatment.

\section{Introduction}

As the fifth common human malignancy, hepatocellular carcinoma (HCC) is the third leading cause of cancer-associated mortality worldwide (1). Traditional therapeutic strategies, including surgery, are often ineffective in controlling HCC or prolonged HCC-associated survival, partially due to late diagnoses $(2,3)$. Transarterial embolization (TAE), including transarterial chemoembolization (TACE), is a common therapeutic strategy for patients with stage B HCC who are unable to undergo surgical resection (4). During TAE/TACE, an emulsion of materials that includes chemotherapeutic drugs is injected into the tumor-feeding arteries, thereby blocking the blood supply to the tumor, leading to ischemia, hypoxia and necrosis of the tumor tissues (5). Studies have indicated that TAE/TACE is effective in controlling HCC (6). However, tumor recurrence and poor prognosis frequently occur subsequent to TAE/TACE. Although significant 
advances have been achieved in the treatment of HCC, such as gene therapy and immunotherapy (7-10), these strategies for patients are currently limited in use due to the high-cost and time-consuming nature. Therefore, the current therapies, such as TAE, in combination with other novel technologies against HCC may be an affordable and feasible approach.

Precise gene knockout technology for editing the human genome has been applied to translational medicine, and the CRISPR/Cas9 (also known as clustered regularly interspaced short palindromic repeats/CRISPR-associated protein 9) system is one of the outstanding methods (11). CRISPR/Cas9 is a bacterial system with endonucleases involved in adaptive immunity. The system can effectively target intended genomic loci by a small guide RNA (sgRNA), which is composed of a target complementary CRISPR RNA (crRNA) and an auxiliary trans-activating crRNA (tracrRNA) (12). Technologically, through a delivery vector, such as a lentiviral vector, designed sgRNAs and CRISPR/Cas9 can be expressed in a certain cell. When the CRISPR/Cas9 endonuclease targets a specific genomic locus through base pairing between the crRNA sequence and the target DNA sequence, a double-stranded DNA break is formed, and a targeted gene modification is achieved, causing gene disruption, which is much more efficient than the effect of other nucleases, such as Zinc finger nucleases (ZFNs) and transcription activator-like effector nucleases (TALENs) (13). In addition, Genetic landscape and biomarkers of HCC have a clear delineation (14). Therefore, the CRISPR/Cas9 system, as a powerful gene-editing tool, is promising in the preclinical and clinical treatment of HCC, which is mainly caused by genetic mutations and an abnormally high expression of key oncogenic proteins.

Hypoxia inducible factor- $1 \alpha$ (HIF-1 $\alpha)$, a hypoxia-induced oxygen-dependent transcription factor, play a vital role in the aggressiveness, angiogenesis and chemotherapy resistance of HCC, as well as in the maintenance of liver cancer stem cells (15). Particularly, HIF-1 $\alpha$ activates the hypoxic pathways, leading to the overexpression of vascular endothelial growth factor (VEGF), triggering epithelial mesenchymal transition, tumor invasiveness and metastasis by promoting the expression levels of matrix metalloproteinase 2 (MMP2) and MMP9 $(16,17)$. Our previous study demonstrated that HIF-1 $\alpha$ was upregulated in HCC, and was associated with hepatic capsular invasiveness and portal vein metastasis (18). Additionally, the expression of multi-drug resistance protein (MDR) is also under the control of HIF-1 $\alpha$, and its protein product $\mathrm{P}$-glycoprotein $(\mathrm{P}-\mathrm{gp})$ is capable of transporting chemotherapeutic drugs out of cells. Tumor cells with an excessive expression of P-gp are generally resistant to chemotherapeutic drugs (19). Notably, it has been reported that TAE/TACE induced liver hypoxia, and that the expression levels of HIF-1 $\alpha$ in the serum and HCC tissues were significantly higher in patients who underwent TACE compared with those in the control group (20). High recurrence rates and metastases of HCC following TACE treatment are also involved in the HIF-1 $\alpha$-associated drug-resistance and hypoxia-tolerance (21). Thus, the inhibition of HIF- $1 \alpha$ in combination with TAE may be a promising therapeutic approach against HCC.

In the present study, a lentivirus-mediated CRISPR/Cas9 system targeting the human HIF-1 $\alpha$ gene was used to analyze the role of HIF-1 $\alpha$ in the human liver cancer cell line SMMC-7721.
The lentivirus-mediated HIF-1 $\alpha$ disruption suppressed cell proliferation, migration and invasiveness, and induced apoptosis under $\mathrm{CoCl}_{2}$-induced hypoxic conditions. HIF-1 $\alpha$ disruption also significantly inhibited SMMC-7721 xenograft tumor growth in the liver and prolonged the survival of HCC-bearing mice treated with hepatic artery ligation (HAL). These findings suggested that CRISPR/Cas9-based HIF-1 $\alpha$ disruption improved the antitumor efficacy of HAL and further highlighted the possibility that HIF-1 $\alpha$ may be an ideal knockout target for the treatment of HCC in combination with TAE.

\section{Materials and methods}

HCC patient data and tissue specimens. A total of 20 matched pairs of HCC and normal adjacent liver tissues were acquired during surgery between May 2014 and April 2016 at the Shenzhen People's Hospital (Shenzhen, China). Patients met the following criteria according to our previous work: i) male/female patient ratio was 1:1, patients ranged in age from 35 to 75 years; ii) HCC patients were newly diagnosed with liver function tests of Child-Pugh grade A; iii) without history of anticancer therapy; iv) without any distant metastasis; v) without other types of malignant tumors, autoimmune, liver disease or serious heart, lung, kidney, or blood disease; and vi) seronegative for hepatitis $\mathrm{B}$ surface antigen and $\mathrm{HCV}$. The samples were either snap-frozen or stored in liquid nitrogen for protein extraction or fixed in formalin and embedded in paraffin for immunohistochemistry analysis.

Construction of the pLenti-CAS9-sgRNA719/720/721-egfp vectors. sgRNAs were designed using the Optimized CRISPR Design tool (http://crispr.mit.edu/) as follows: sgRNA719, 5'-CCTCACACGCAAATAGCTGA-3'; sgRNA720, 5'-TAC TCATCCATGTGACCATG-3'; and sgRNA721, 5'-GTTATG GTTCTCACAGATGA-3'. LV-Ctrl was constructed as control lentiviruses that did not have any sgRNAs used for targeting the HIF-l $\alpha$ gene. The cDNAs encoding the sgRNAs for 3 gene knockout sites in the first exon of the $H I F-1 \alpha$ gene were synthesized and purified (Invitrogen; Thermo Fisher Scientific, Inc., Waltham, MA, USA). Different programmed lentiviral plasmids based on the pLenti-CAS9-sgRNA-egfp (GeneChem Co., Ltd., Shanghai, China) were constructed as previously described (22).

Packaging and purification of the modified CRISPR/Cas 9 lentiviruses. The CRISPR/Cas9 lentivirus production was performed following previously described protocols (22). Briefly, 12 145-mm Petri dishes were prepared and $1 \times 10^{7}$ HEK293T cells [American Type Culture Collection (ATCC) Manassas, VA, USA] were seeded in each dish with Dulbecco's modified Eagle's medium (Gibco; Thermo Fisher Scientific, Inc.) containing $10 \%$ fetal bovine serum (FBS; Gibco; Thermo Fisher Scientific, Inc.). pLenti-CAS9-sgRNA-egfp (20 $\mu \mathrm{g})$, psPAX2 (15 $\mu \mathrm{g}$; Addgene, Inc., Cambridge, MA, USA), pMD2.G plasmid (10 $\mu \mathrm{g}$; Addgene, Inc., Cambridge, MA, USA) and linear PEImax (Polysciences, Inc., Warrington, PA, USA) were mixed and added to the HEK293T cells in each dish. After $6 \mathrm{~h}$ of incubation in a $\mathrm{CO}_{2}$ incubator at $37^{\circ} \mathrm{C}$, the medium was replaced with complete medium. After $48 \mathrm{~h}$, the cell supernatants were filtered through a $0.45-\mu \mathrm{m}$ filter 
(EMD Millipore, Billerica, MA, USA). Subsequently, supernatants were ultracentrifuged (Beckman Coulter, Inc., Brea, CA, USA) at 20,000 $\mathrm{x}$ g for $2 \mathrm{~h}$ at $4^{\circ} \mathrm{C}$, and the lentiviruses were suspended in PBS and stored at $-80^{\circ} \mathrm{C}$.

Lentivirus infection in SMMC-7721 cells and the T7 endonuclease 1 assay (T7E1) of HIF-1 $\alpha$-knockout. The titer of the concentrated lentiviruses was determined by a quantitative polymerase chain reaction (qPCR) method as described previously with 293T cells (23). Subsequently, SMMC-7721 cells (ATCC) were cultured in Dulbecco's modified Eagle's medium (Gibco; Thermo Fisher Scientific, Inc.) with 10\% FBS and 1\% penicillin-streptomycin (Gibco; Thermo Fisher Scientific, Inc.) in a $\mathrm{CO}_{2}$ incubator at $37^{\circ} \mathrm{C}$. SMMC-7721 cells were infected with the lentivirus at a multiplicity of infection (MOI) of 2.5. To check the total percentage of GFP-positive cells, single-cell suspensions were prepared in PBS plus 2\% FBS from trypsinized cells at 72-h after infection. After resuspension, cells were subjected to fluorescence activated cell sorting (FACS) analysis with a BD Accuri C6 flow cytometer (BD Biosciences, San Jose, CA, USA) as described (22). Next, SMMC-7721 cell genomic DNA was extracted using a DNeasy Blood \& Tissue kit (Qiagen, Hilden, Germany). A mismatch-sensitive T7E1 Assay kit (New England BioLabs, Inc., Ipswich, MA, USA) was then used to confirm CRISPR/Cas9 cleavage and targeted sequence disruption, according to the manufacturer's protocol. Subsequently, the PCR fragments containing each knockout gene locus were cloned with primers in different group using a Takara PCR amplification kit (cat. no. DR011; Takara Bio, Inc., Otsu, Japan) according to the manufacturer's protocols. The following primers were used: i) LV-H719+7721 cells group: 5'-TCTAATCCTTCTGTGATAAGCAG-3' (forward) and 5'-CAAAATCAAAACATTGCGACCAC-3' (reverse); ii) LV-H720 + 7721 cells group: 5'-ACATGAAAGCACAGA AATTGC-3' (forward) and 5'-TGCCTTGGGTAAGTACAA TAGC-3' (reverse); and iii) LV-H721 + 7721 cells group: H721, 5'-TCTTCTTGTGCCCTTTTTAGGTG-3' (forward) and 5'-CTTACCATTTCTGTGTGTAAGC-3' (reverse). The cloned DNA sequences were then inserted into a plasmid using pMD19-T (Takara Bio, Inc., Otsu, Japan) for DNA sequencing (Invitrogen; Thermo Fisher Scientific, Inc.) and comparison. The SMMC-7721 cell line where HIF-1 $\alpha$ has been successfully knockout after LV-H721 infection at MOI=2.5 was established and was named as 7721-HIF-1 $\alpha$-KO cells for further testing.

Reverse transcription- $q P C R$ analysis of the mRNA expression levels of vegf and mdrl genes. The total cell RNA was extracted using the TRIzol reagent (Invitrogen; Thermo Fisher Scientific, Inc.) according to the manufacturer's protocol. The concentration and the quality of RNAs were measured with a NanoDrop 8000 (Thermo Fisher Scientific, Inc.). A PrimeScript ${ }^{\circledR}$ II First Strand cDNA synthesis kit (cat. no. H6210B; Takara Bio, Inc.) was used to synthesize the cDNA. Subsequently, the gene mRNA expression levels were detected by qPCR using Thunderbird SYBR-Green qPCR Mix (cat. no. QPS-201; Toyobo Life Science, Osaka, Japan) according to the manufacturer's protocol. Primers used in this experiment were as follows: vegf, 5'-TGCTCTACCTCCACC ATGCCA-3' (forward) and 5'-GAAGATGTCCACCAGGGT CTCG-3' (reverse); $m d r 1$, 5'-TGATGCTGCTCAAGTTAA
AGGG-3' (forward) and 5'-TTGCCAACCATAGATGAAGGA TAT-3' (reverse); $\beta$-actin, 5'-GTCCACCGCAAATGCTTC TA-3' (forward) and 5'-TGCTGTCACCTTCACCGTTC-3' (reverse); and $g f p, 5^{\prime}$-TGCTTCAGCCGCTACCC-3' (forward) and 5'-AGTTCACCTTGATGCCGTTC-3' (reverse).

Protein sample preparation and western blotting. Protein samples from patient tissues and SMMC-7721 cells were prepared using radio-immunoprecipitation assay lysis buffer (RIPA; Beyotime Institute of Biotechnology, China), and the protein concentration was detected by the BCA protein quantitation kit (Bio-Rad Laboratories, Inc., Hercules, CA, USA). Western blot analysis was then performed based on protocols reported in a previous study (22). The following primary and secondary antibodies were used: Anti-VEGF (cat. no. 19003-1-AP; 1:2,000, ProteinTech, Inc., Chicago, IL, USA), anti-MDR1 (cat. no. PA5-28810; 1:2,000, Thermo Fisher Scientific, Inc.), anti-HIF-1 $\alpha$ (cat. no. 20960-1-AP; $1: 2,000$, ProteinTech, Inc.), anti- $\beta$-actin (cat. no. MA1-140; 1:2,000, Thermo Fisher Scientific, Inc.), horseradish peroxidase (HRP)-conjugated anti-rabbit IgG (cat. no. 7074; 1:2,000, Cell Signaling Technology, Inc., Danvers, MA, USA) and HRP-conjugated anti-mouse IgG (cat. no. 7076; 1:2,000; Cell Signaling Technology, Inc.) antibodies.

MTT assay, apoptosis and cell cycle detection. SMMC-7721 cells were cultured in 96-well $\left(10^{4}\right.$ cells per well) or 6-well ( $3 \times 10^{5}$ cells per well) plates. A total of $150 \mu \mathrm{M}$ cobalt chloride ( $\mathrm{CoCl}_{2}$; Sigma-Aldrich; Merck KGaA, Darmstadt, Germany), a well-known hypoxia mimetic $(24,25)$, was used to mimic tumor hypoxic conditions. In order to examine the cell proliferation, at $8 \mathrm{~h}$ after the lentivirus infection, $20 \mu \mathrm{l} \mathrm{MTT}(5 \mathrm{mg} / \mathrm{ml})$ was added to each sample and incubated for $3 \mathrm{~h}$. The formazan crystals were dissolved in dimethyl sulfoxide $(150 \mathrm{ml} /$ well $)$, and the absorbance of each sample at $490 \mathrm{~nm}$ was measured.

For cell apoptosis analysis, a PE-Annexin V Apoptosis Detection kit (cat. no. 559763; BD Biosciences) was used. Briefly, $5 \mu \mathrm{l}$ of Annexin V-PE and $5 \mu \mathrm{l}$ of 7-AAD were added in $100 \mu \mathrm{l}$ cell suspension with $1 \mathrm{x}$ binding buffer plus $5 \% \mathrm{FBS}$, and incubated for $15 \mathrm{~min}$ in the dark. Finally, cells were washed twice and diluted with buffer and immediately subjected to FACS analysis (22). For the detection of cell cycle progression, PI-RNase solution (cat. no. 550825; BD Biosciences) was used, according to the manufacturer's protocol. Flow cytometry was then performed using a BD FACS Arial flow cytometer (BD Biosciences), and the results were analyzed with FlowJo software (Tree Star, Inc., Ashland, OR, USA).

Transwell and scratch wound assay. A Transwell system with a $6.5-\mathrm{mm}$ diameter and an $8.0 \mu \mathrm{m}$ pore polycarbonate filter membrane (Corning Inc., Corning, NY, USA) was used, and Matrigel (cat. no. 356234; Corning Inc.) was used to form a thin gel layer on the wells. At $12 \mathrm{~h}$ after infection, the SMMC-7721 cells $\left(1 \times 10^{5}\right.$ per well) were added to the upper chamber. In the lower chambers, 20\% FBS was added as a chemoattractant. $\mathrm{CoCl}_{2}(150 \mu \mathrm{M})$ was added to simulate hypoxia in both upper and lower chambers. After $24 \mathrm{~h}$, the cells that had penetrated to the lower surface of the filter were stained with crystal violet and counted using a Nikon microscope (Nikon Corporation, Tokyo, Japan). 
A scratch wound assay was also performed. Briefly, the SMMC-7721 cells were seeded into 6 -well plates $\left(3 \times 10^{5}\right.$ per well). Following infection with lentivirus after $12 \mathrm{~h}$, a linear wound was created in the monolayer with a sterile $100-\mu 1$ plastic pipette tip, and cells were then gently washed with PBS immediately. Cells were cultured under the $\mathrm{CoCl}_{2}$-simulated hypoxic conditions and then observed under the microscope.

Establishment of SMMC-7721-Fluc cells. The overlapping gene $m F l u c 2$, which included the $m$ Cherry fluorophore and Fluc2 gene (the gene that expresses the firefly luciferase protein), was cloned from the pmCherry- $\mathrm{C} 1$ (Clontech Laboratories, Inc., Mountainview, CA, USA) and pGL4.17 plasmids (Promega Corp., Madison, WI, USA) using a Takara PCR amplification kit. The PCR cycling conditions were set as follows: $1 \mathrm{~min}$ at $95^{\circ} \mathrm{C}$ for denaturation, 45 cycles of $95^{\circ} \mathrm{C}$ for $30 \mathrm{sec}$, and $55^{\circ} \mathrm{C}$ for $30 \mathrm{sec}$, then $72^{\circ} \mathrm{C}$ for $1 \mathrm{~min}$. Lastly $1 \mathrm{~h} \mathrm{~s}$ at $4^{\circ} \mathrm{C}$. Next, the pWPXLd-mFluc2 plasmid was constructed, and the LV-mFluc lentivirus was packaged according to previous methods (22). The SMMC-7721 cells were infected with LV-mFluc with an MOI of 2.5, and the mCherry-positive SMMC-7721 cells were purified by flow cytometry (BD FACS Arial device) and cloned. Subsequently, a dual-luciferase reporter assay in the intended SMMC-7721-Fluc cells was conducted using the Dual-Luciferase ${ }^{\circledR}$ Reporter Assay system according to the manufacturer's protocol (cat. no. E1910; Promega Corp. Madison, CA, USA). The primers used in this experiment are as follows: Clone for $m$ Cherry gene: 5'-GGGGATCCA TGGTGAGCAAGGGCGAGGAGGATA-3' (forward) and 5'-TCTTTATGTTTTTGGCGTCTTCCATCTTGTACAGCT CGTCCATGCCGCCG-3' (reverse); and clone for Fluc gene, 5'-CGGCGGCATGGACGAGCTGTACAAGATGGAAGA CGCCAAAAACATAAAGA-3' (forward) and 5'-ACGGAA TTCTCACTCGAGCAATTTGGACTTTCCG-3' (reverse).

Animals and CRISPR/Cas9 treatment in vivo. Seventy male $\mathrm{BALB} / \mathrm{c}$ nu/nu mice (4-6 weeks old, 16-20 g) were purchased from the Shanghai SLAC Laboratory Animal Co., Ltd. [license no. SCXK (HU) 2007-0003; Shanghai, China]. Mice were housed in specific pathogen-free (SPF) conditions, with a 12-hours light cycle and food and water at ad libitum. In order to establish a subcutaneous HCC model, $4 \times 10^{6}$ SMMC-7721 cells were injected in the right flank of the mouse subcutaneously ( $n=4 /$ group). After 9 days, $5 \times 10^{7}$ LV-H721, which was a lentivirus-mediated CRISPR/Cas system with small guide RNA-721, were injected into the tumor tissues. Tumor tissues injected with PBS or LV-Ctrl (a lentivirus without CRISPR/Cas system targeting HIF-1 $\alpha$ ) were used as control groups. The tumors were harvested 3 days post LV-infection for immunohistochemical examination.

The procedure for the establishment of the orthotopic liver tumor model was conducted according to a previously described method (26). Briefly, pentobarbital was dissolved in saline to obtain a $10 \mathrm{mg} / \mathrm{ml}$ solution. Mice were anesthetized with pentobarbital $(50 \mathrm{mg} / \mathrm{kg})$ through intraperitoneal injection and placed in a supine position. A small transverse incision was made below the sternum to expose the liver. A total of $5 \times 10^{6}$ control lentivirus-infected SMMC-7721-Fluc cells (7721) or LV-H721-infected SMMC-7721-Fluc cells at $48 \mathrm{~h}$ after infection were suspended in $50 \mu 1 \mathrm{PBS}$ and slowly injected into each mouse liver. At 5 days after implantation, mice were subdivided into four groups as follows: i) 7721-induced HCC + sham surgery $(\mathrm{Ctrl} ; \mathrm{n}=8)$; ii) 7721-induced HCC + HAL surgery $(\mathrm{n}=8)$; iii) control lentivirus-infected 7721-induced $\mathrm{HCC}+\mathrm{HAL}$ (HAL+LV-Ctrl; $\mathrm{n}=8$ ); and iv) LV-H721-infected 7721-induced $\mathrm{HCC}+\mathrm{HAL}(\mathrm{HAL}+\mathrm{LV}-\mathrm{H} 721 ; \mathrm{n}=8)$. HAL was performed in the mice by ligating the main branch of the hepatic artery. The tumor volume was measured by bioluminescence imaging with $200 \mu 1$ D-luciferin potassium salt solutions $(15 \mathrm{mg} / \mathrm{ml}$; Sigma-Aldrich; Merck KGaA) after HAL during 2 weeks. After 2 weeks, the mice ( $\mathrm{n}=5 /$ group) were sacrificed and mouse tumor samples were collected for immunohistochemistry analysis. Furthermore, an extended observation of tumor-bearing mice with four different treatments was carried out again, and the mouse overall survivals were recorded.

Immunohistochemical staining for HIF-1 $\alpha$ and CD31 expression in tissues. Human or SMMC-7721-induced mouse tumor tissues were fixed with $4 \%$ neutral paraformaldehyde. Next, the paraffin-embedded sections (human and mouse tumor tissues) were incubated with the anti-HIF-1 $\alpha$ antibody (cat. no. 20960-I-AP; 1:100; ProteinTech, Inc., Rosemont, IL, USA) overnight at $4^{\circ} \mathrm{C}$, followed by incubation with 50-100 $\mu \mathrm{l}$ $1 \mathrm{x}$ the secondary antibody solution for 1-h (cat. no. KIHC-5, 1:1, ProteinTech, Inc.). The signals were detected by staining the sections with 3,3'-diaminobenzidine (DAB; ProteinTech, Inc.) and hematoxylin. Furthermore, to monitor the microvascular density (MVD), the mouse tumor sections were stained with an anti-CD31 monoclonal antibody overnight at $4^{\circ} \mathrm{C}$ (cat. no. 14-0319-80; 1:300, Thermo Fisher Scientific, Inc.), and the rest of the test was carried out as previously described.

TUNEL staining assay for cell apoptosis in vivo. The DeadEnd $^{\mathrm{TM}}$ Colorimetric TUNEL System (cat. no. G7130, Promega Corp.) was used for the TUNEL staining assay. Briefly, the tumor slides were incubated with terminal deoxynucleotide transferase (TdT) and a biotinylated nucleotide mixture at $37^{\circ} \mathrm{C}$ for $30 \mathrm{~min}$. Subsequently, the endogenous peroxidases was blocked by immersing the slides in $0.3 \%$ hydrogen peroxide in PBS for 3-5 min at room temperature. The slides were incubated with streptavidin-HRP and visualized with DAB. Negative controls were set up by substituting distilled water for TdT in the working solution. The results are presented as the ratio of the TUNEL-positive cells to the total number of cells.

Statistics analysis. The statistical analysis was performed with SPSS version 17.0 software (SPSS, Inc., Chicago, IL, USA). All the data were analyzed using one-way analysis of variance followed by least significant difference post-hoc analysis, or using an unpaired two-tailed Student's t-test (as appropriate). The survival curves were obtained by Kaplan-Meier analysis, and the prognostic significance was analyzed by the log-rank test. Statistically significant differences were denoted by $\mathrm{P}<0.05$. All data were acquired from four repeated experiments.

\section{Results}

HIF-1 $\alpha$ is overexpressed in human HCC tissues and in SMMC-7721-induced HCC xenograft tissues in mice. The 
A

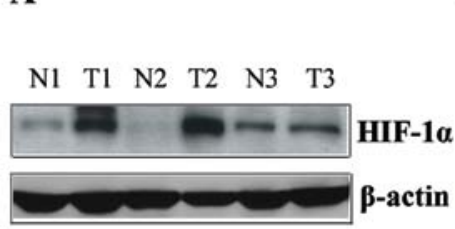

B

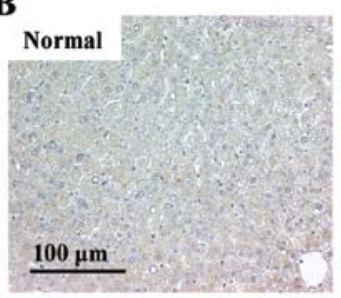

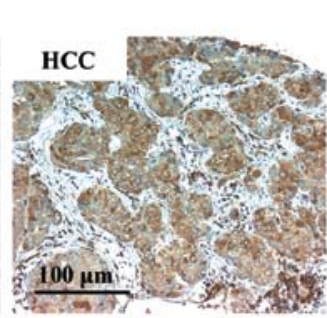

Figure 1. HIF-1 $\alpha$ protein is highly expressed in human HCC tissues. (A) Western blot analysis and (B) IHC staining (bars, $100 \mu \mathrm{m}$ ) of HIF-1 $\alpha$ protein in HCC and normal liver tissues with x 20 magnification. (C) Mean \pm standard deviation of the IHC score of HIF-1 $\alpha$ in 20 paired HCC tissues. ${ }^{*}<<0.05$. HIF-1 $\alpha$, hypoxia inducible factor-1 $\alpha$; HCC, hepatocellular carcinoma; IHC, immunohistochemical; N, normal liver tissues; T, HCC tissues.

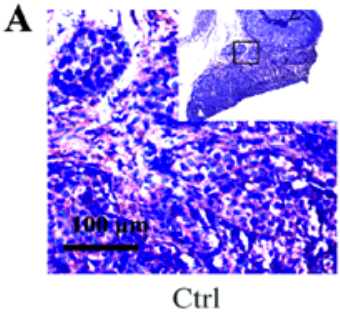

B

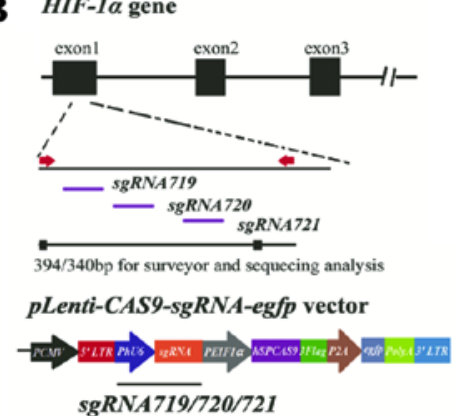

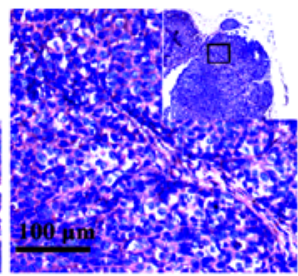

LV-Ctrl

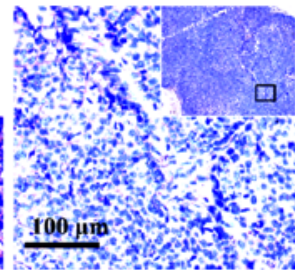

LV-H721

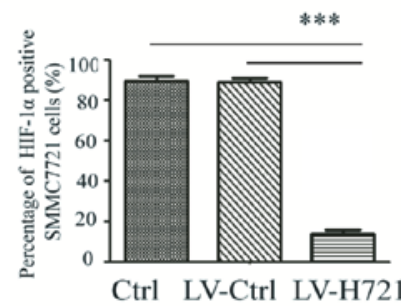

D
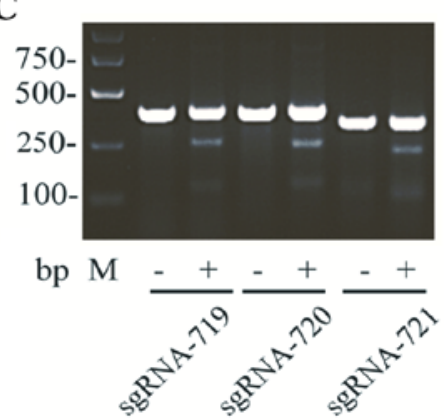

$\mathbf{E}$

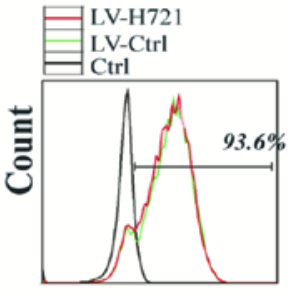

F

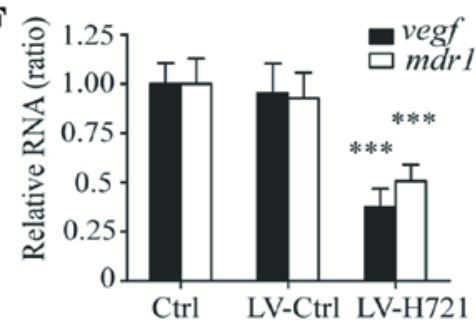

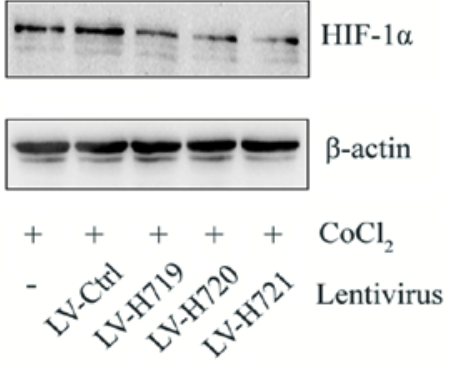

G

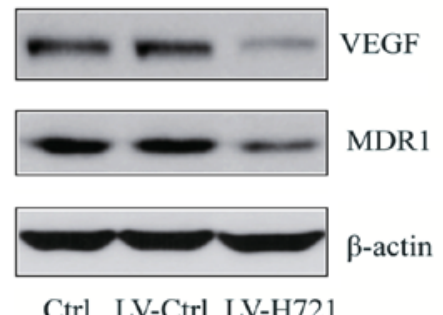

Figure 2. Generation of the CRISPR/Cas9-based lentivirus and HIF-1 $\alpha$ knockout in SMMC-7721 cells and in the SMMC-7721-induced tumor tissues of mice. (A) Immunohistochemical analysis for the detection of HIF-1 $\alpha$ expression in hepatocellular carcinoma tissues following infection with LV-Ctrl or LV-H721 in the subcutaneous animal model (bars, $100 \mu \mathrm{m}$ ). (B) Diagram illustration of the lentiviral vector (Lenti-CAS9-sgRNA-egfp). Three sgRNAs (sgRNA719, sgRNA720 and sgRNA721) targeting HIF-1 $\alpha$ were designed, and Lenti-CAS9-sgRNA719/720/721 plasmids were constructed. (C) Gel electrophoresis and DNA analysis of the HIF-1 $\alpha$ genomic frame shift mutation conducted after the T7E1 endonuclease assay in SMMC-7721 cells infected with LV-Ctrl or LV-H719/720/721. (D) Western blot analysis of HIF-1 $\alpha$ expression in the different lentivirus-infected SMMC-7721 cells with CoCl ${ }_{2}$-simulated hypoxia. (E) GFP-positive cells analyzed by flow cytometry following infection with LV-Ctrl and LV-H721. (F) Relative mRNA and (G) protein expression levels of VEGF and MDR1 in different cell groups were examined by reverse transcription-quantitative polymerase chain reaction and western blot analysis. $\beta$-actin served as an internal control. Data are a representation of four repeated experiments, and histograms represent the mean \pm standard deviation. ${ }^{* * * *} \mathrm{P}<0.001$. sgRNA, small guide RNA; Ctrl, control; LV, lentivirus; HIF-1 $\alpha$, hypoxia inducible factor-1 $\alpha$; VEGF, vascular endothelial growth factor; MDR1, multi-drug resistance protein 1 .

expression levels of HIF-1 $\alpha$ protein were first analyzed in 20 paired HCC and normal adjacent liver tissues by western blot and immunohistochemical analyses. As shown in Fig. 1A and B, the HIF-1 $\alpha$ protein levels in the HCC tissues were higher in comparison with those in the normal adjacent liver tissues, and the difference was found to be statistically significant $(\mathrm{P}<0.05$; Fig. $1 \mathrm{C})$.
SMMC-7721 cells, a human liver cancer cell line, were also used to establish an HCC model in BALB/c nu/nu mice. The results revealed that the implanted HCC cells had a significantly higher expression of HIF-1 $\alpha$ protein as compared with the control groups (Fig. 2A). Subsequently, the SMMC-7721-induced HCC model was used in further CRISPR/Cas9-mediated $H I F-1 \alpha$-knockout experiments. 


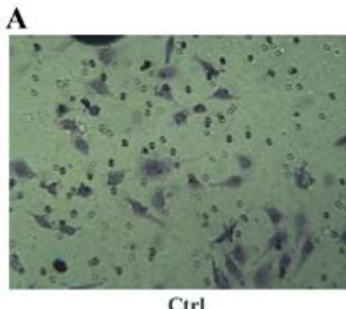

Ctrl

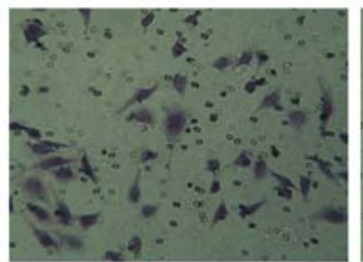

B

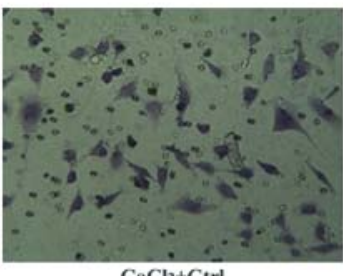

$\mathrm{CoCl}_{2}+\mathrm{Ctrl}$

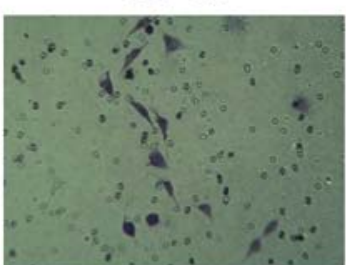

$\mathrm{CoCl} 2+\mathrm{LV}-\mathrm{H} 721$
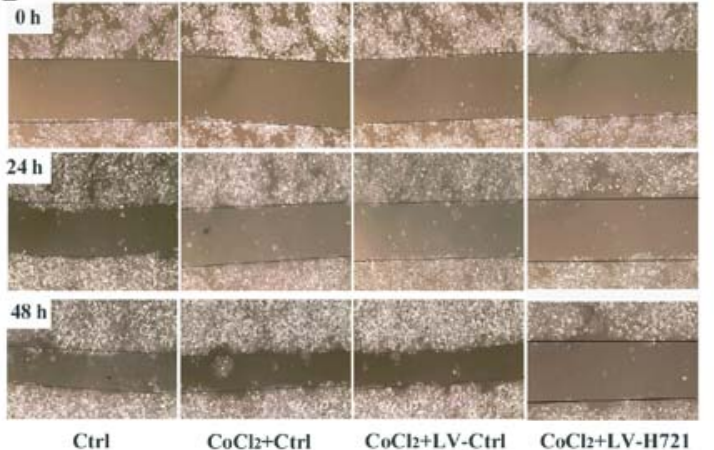
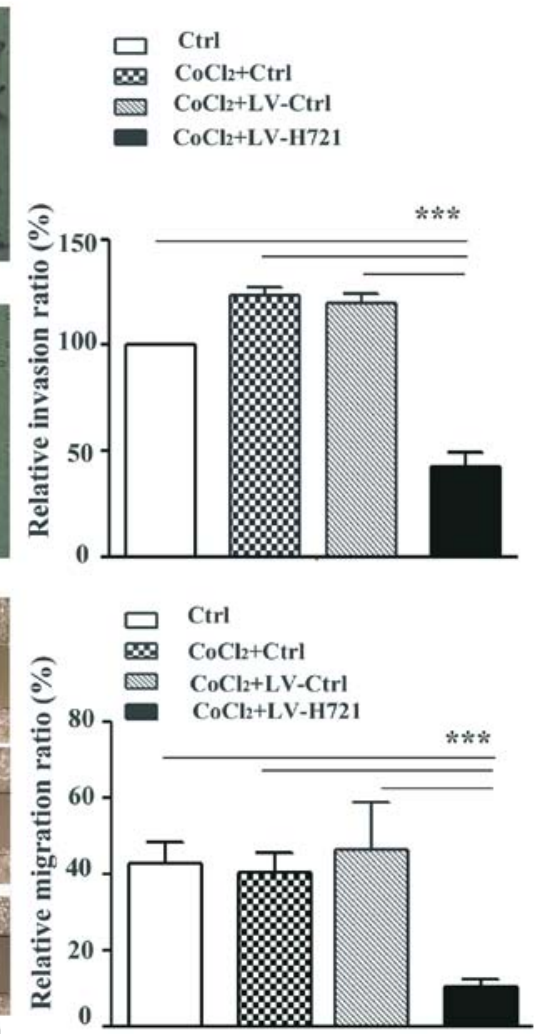

Figure 3. Hypoxia inducible factor- $1 \alpha$ disruption reduces the invasiveness and migration potency of lentivirus-infected $\mathrm{SMCC}-7721$ cells under $\mathrm{CoCl} \mathrm{C}_{2}$-induced hypoxic conditions. (A) Cell invasiveness was measured with the Matrigel transwell assay at $24 \mathrm{~h}$ post treatment with $\mathrm{x} 20$ magnification. (B) Scratch-wound assay for cell migration was conducted at 24 and $48 \mathrm{~h}$ post infection under hypoxia with $\mathrm{x} 20$ magnification. Bar graphs represent the mean percentage \pm standard deviation of the cell invasion/migration ratio. ${ }^{* * *} \mathrm{P}<0.001$. Ctrl, control; LV, lentivirus.

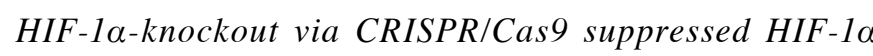
expression. To identify sgRNAs specifically targeting the gene loci of $H I F-1 \alpha$, three sgRNAs were designed to target the first exon of $H I F-l \alpha$ according to guidelines of the Optimized CRISPR Design online tool (Fig. 2B). The pLenti-CAS9-sg RNA719/720/721-egfp plasmids, based on the pLenti-CAS9 vector, were established (Fig. 2B). The CRISPR/Cas9 lentiviruses with different sgRNAs were labeled as LV-H719, LV-H720 and LV-H721. Subsequently, SMMC-7721 cells were infected with the lentiviruses at an MOI of 2.5, and the gene disruption efficacies were assessed, followed by the T7E1 endonuclease assay and DNA sequencing. The results demonstrated that all three sgRNAs led to DNA frameshift mutations and had high gene disruption efficiencies (Fig. 2C). Furthermore, the results of the western blot analysis revealed that LV-H721 infection significantly reduced the expression of HIF1- $\alpha$ with the maximum efficiency (Fig. 2D). The percentage of total GFP-positive cells in LV-H721-infected SMMC-7721 cells was also measured to assess the lentiviral transfection efficiency, and was found to be $93.6 \%$ (Fig. 2E). LV-Ctrl (a lentivirus without CRISPR/Cas system targeting $H I F-1)$ could also express GFP in the infected SMMC-7721 cells and had equal lentiviral transfection. It was observed that $H I F-1 \alpha$ knockout caused by LV-H721 transfection in the cells was observed to significantly downregulate the mRNA levels of vegf and $m d r l$ as compared with those in the control groups (all $\mathrm{P}<0.001$; Fig. 2F). As shown in Fig. 2G, the expression levels of the VEGF and MDR1 protein, which has been reported to be under the control of HIF-1 $\alpha$ (17), were also inhibited in the present study. Thus, LV-H721 was used as a CRISPR/Cas9-mediated vector for further experiments.

The efficiency of LV-H721-mediated HIF-1 $\alpha$ knockout was also examined in the mice. The SMMC-7721 xenograft HCC tissues were harvested 3 days post LV infection. Immunohistochemical examination revealed that HIF- $1 \alpha$ was highly expressed in the control and LV-Ctrl-treated HCC tissues. Furthermore, the expression of HIF-1 $\alpha$ was significantly reduced in the LV-H721-treated tissues when compared with those in the control groups (both $\mathrm{P}<0.001$; Fig. 2A). Collectively, these data indicated that the lentivirus-mediated CRISPR/Cas9 efficiently disrupted the expression levels of $H I F-l \alpha$ gene and its targets, including VEGF and MDR1, in liver cancer cells and xenograft tumor tissues.

HIF-1 $\alpha$ knockout impairs cell invasion and migration. First, the effect of the CRISPR/Cas9 based HIF-l $\alpha$ knockout on migration and invasion was determined in the SMMC-7721 cells (7721-HIF- $1 \alpha-\mathrm{KO})$. The SMMC-7721 cells were infected with the lentiviruses, and $\mathrm{CoCl}_{2}$, a well-known hypoxia mimetic, was used to simulate the hypoxic conditions in vitro. In the transwell invasion assay, the number of invasive 7721-HIF-1 $\alpha$-KO cells (namely the $\mathrm{CoCl}_{2}+\mathrm{LV}-\mathrm{H} 721$ group) that penetrated the polycarbonate filter was significantly reduced, and this difference was statistically significant (both $\mathrm{P}<0.001$; Fig. 3A). Meanwhile, 7721-HIF-1 $\alpha$-KO cells exhibited further reduced relative migration rates at 24 and $48 \mathrm{~h}$ 
A

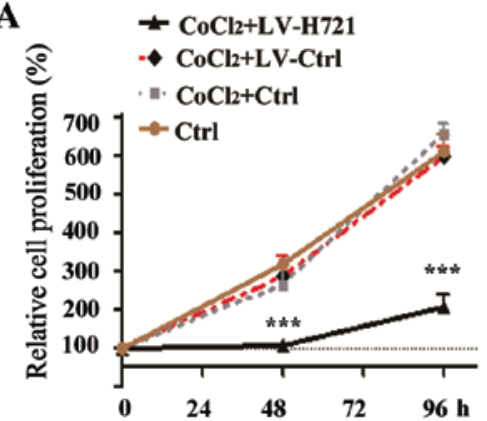

D

Ctri
B

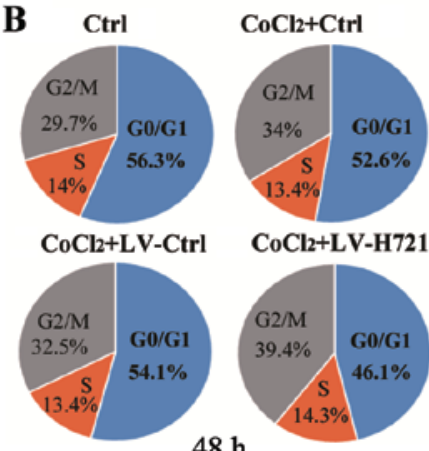

$48 \mathrm{~h}$

$\mathrm{CoCl}_{2}+\mathrm{LV}-\mathrm{Ctrl} \mathrm{CoCl}_{2}+\mathrm{LV}-\mathrm{H} 721$

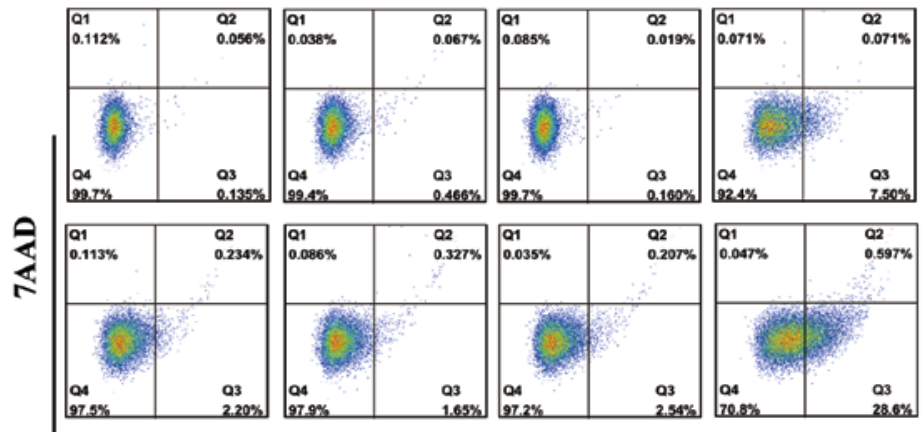

Annexin V-PE

C
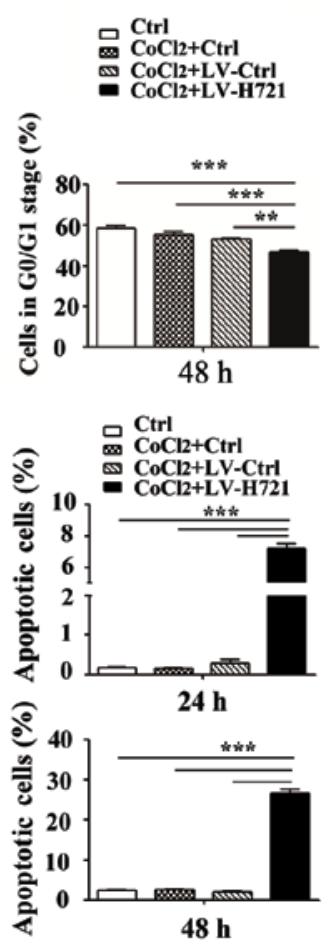

Figure 4. Hypoxia inducible factor- $1 \alpha$ knockout leads to a reduced cell proliferation rate and increased apoptosis in the SMMC-7721 cells. Cells were infected with LV-Ctrl and LV-H721 under hypoxic conditions. (A) MTT assay showing the cell growth characteristics following lentivirus infection for 4 days. Statistically significant differences were denoted between $\mathrm{CoCl}_{2}+\mathrm{LV}-\mathrm{H} 721$ group and the other three groups correspondingly $\left(\mathrm{Ctrl}, \mathrm{CoCl}{ }_{2}+\mathrm{Ctrl}\right.$, and $\mathrm{CoCl}_{2}+\mathrm{LV}-\mathrm{Ctrl}$ groups, all ${ }^{* * *} \mathrm{P}<0.001$ ). (B) Cell cycle distribution and (C) percentage of cells in G0/G1 stage in each group, as determined by flow cytometry analysis under $\mathrm{CoCl}_{2}$-mimicking hypoxic conditions at $48 \mathrm{~h}$ post infection in vitro. (D) Flow cytometry analysis of cell apoptosis under hypoxic conditions at 24 and 48 h post infection. Bar graphs show the mean percentage \pm standard deviation of the cell ratios. ${ }^{* *} \mathrm{P}<0.01$ and ${ }^{* * *} \mathrm{P}<0.001$. Ctrl, control; LV, lentivirus.

post LV infection compared with the control groups in the scratch-wound assay, and the difference was statistically significant (all $\mathrm{P}<0.001$; Fig. 3B). These results suggested that the disruption of $H I F-1 \alpha$ with the CRISPR/Cas9 system, particularly under the hypoxic microenvironment, inhibited liver cancer cell migration and invasion.

HIF-1 $\alpha$ disruption suppresses cell proliferation and induces cell apoptosis. Hypoxic conditions are reported in the majority of advanced HCC tissues, in particular in patients who undergo TAE. Therefore, the growth characteristics of the $7721-H I F-1 \alpha-\mathrm{KO}$ cells under the hypoxic microenvironment were analyzed using an MTT assay. The optical density, an indicator of the number of viable cells, was monitored subsequent to infection, and a growth curve was plotted (Fig. 4A). The results demonstrated that cell proliferation was profoundly suppressed at 48 and $96 \mathrm{~h}$ post infection between the LV-H721-treated group and the control groups (all $\mathrm{P}<0.001$ ).

Subsequently, the cell cycle progression under hypoxic conditions was assessed at $48 \mathrm{~h}$ post infection in vitro. SMMC-7721 cells infected with LV-H721 exhibited marked changes in their cell cycle progression, and there was an $\sim 10 \%$ decrease in the number of cells in the G0/G1-phase, as well as a concomitant increase in the G2/M-phase (Fig. 4B). However, the S-phase ratio, serving as the marker of cell division, was almost consistent. These data suggested that $H I F-1 \alpha$ knockout did not induce evident cell cycle arrest (Fig. 4B and C). Furthermore, HIF-l $\alpha$ knockout led to a high percentage of early cell apoptosis under hypoxic conditions, and the rates of cell apoptosis were $7.5 \%$ at $24 \mathrm{~h}$ and $28.6 \%$ at $48 \mathrm{~h}$ post infection, with a statistically significant difference observed $(\mathrm{P}<0.001$; Fig. 4D). These results suggested that disruption of $H I F-1 \alpha$ by the CRISPR/Cas9 system inhibited cell proliferation and induced cell apoptosis in the SMMC-7721 cells.

\section{CRISPR/Cas9-mediated HIF-1 $\alpha$ disruption with HAL inhibits} liver tumor growth. The SMMC-772-Fluc cells were established and cloned (data not shown). On days 5, 10, 15 and 20 after implantation of these cells into the mice, the tumor volume was measured by bioluminescence imaging (Fig. 5A). On day 20, the representative features of the tumors in mice with live bioluminescence imaging are shown in Fig. 5B and tumor outlines in mouse livers are shown in Fig. 5C. The results demonstrated that HAL inhibited the progression of $\mathrm{HCC}$ when compared with that observed in the control group $(\mathrm{P}<0.05$; Fig. 5A). Notably, the combination of HAL and LV-H721 exhibited a more significant anti-tumor effect on day 20 as compared with that in the control, HAL and HAL $+\mathrm{LV}-\mathrm{Ctrl}$ groups $(\mathrm{P}<0.001, \mathrm{P}<0.05$ and $\mathrm{P}<0.05$, respectively; Fig. $5 \mathrm{~A})$. Furthermore, the overall median survival results revealed that the combination of HAL $+\mathrm{LV}-\mathrm{H} 721$ significantly prolonged the survival of tumor-bearing mice from $\sim 40$ to 60 days, as compared with the other groups $(\mathrm{P}<0.05$; Fig. 5D), indicating that $H I F-1 \alpha$ disruption enhanced the efficacy of HAL in the treatment of HCC. 


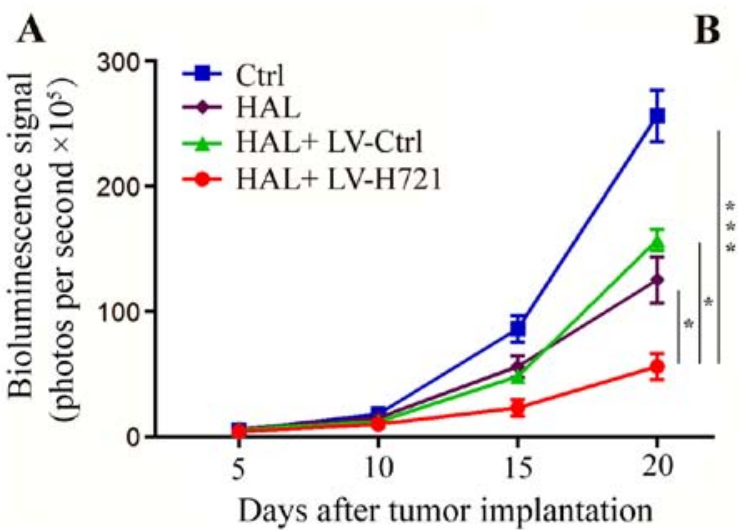

B

C

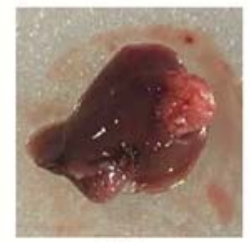

Ctrl

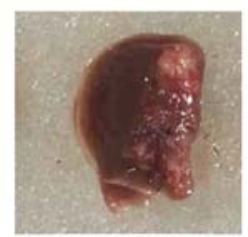

HAL+ LV-Ctrl

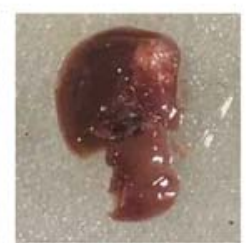

HAL

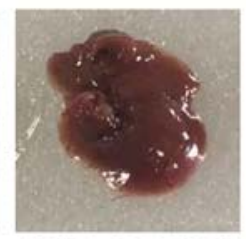

$\mathrm{HAL}+\mathrm{LV}-\mathrm{H} 721$

D

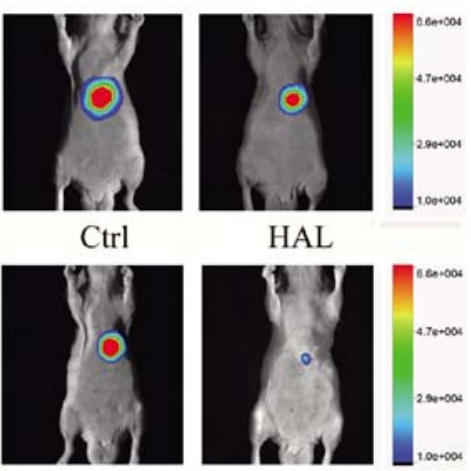

$\mathrm{HAL}+\mathrm{LV}-\mathrm{Ctrl} \mathrm{HAL}+\mathrm{LV}-\mathrm{H} 721$
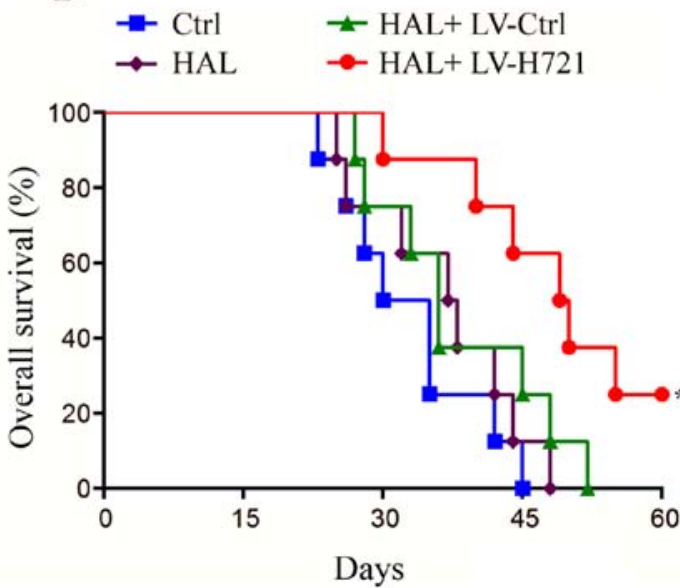

Figure 5. Effect of hypoxia inducible factor-1 $\alpha$ disruption on tumor growth and progression in the mouse orthotopic model. At 5 days after tumor cell implantation, the animals were randomly divided into four groups. (A) Longitudinal monitoring was plotted by the detection of the mean bioluminescence signals on days 5, 10, 15 and 20 after cell implantation (error bars represent the standard error of the mean). (B) Live imaging of the representative tumors on day 20. (C) Tumors of mice sacrificed on day 20, indicating that the tumor volume was evidently decreased in the HAL + LV-H721 group. (D) Animal median survival in each group plotted by the log-rank test. Statistically significant differences were denoted between $\mathrm{HAL}+\mathrm{LV}-\mathrm{H} 721$ group and the other three groups correspondingly (Ctrl, HAL, and HAL $+\mathrm{LV}-\mathrm{Ctrl}$ groups, all $\left.{ }^{*} \mathrm{P}<0.05\right)$. Data are representative of four independent experiments. ${ }^{*} \mathrm{P}<0.05$ and ${ }^{* * *} \mathrm{P}<0.001$. $\mathrm{HAL}$, hepatic artery ligation; Ctrl, control; LV, lentivirus.

Combination of the CRISPR/Cas9-mediated HIF-1 $\alpha$ disruption with HAL inhibits angiogenesis and induces apoptosis in tumor tissues. The expression of CD31 was used as a marker of vascular endothelial cells, or tumor microvascular density (MVD). From immunohistochemical analysis of CD31 protein expression (Fig. 6A), the CD31 was significantly higher in the mice treated with HAL and HAL+ LV-Ctrl as compared with the control group, whereas CD31 was significantly lower in the combined HAL + LV-H721 treatment group in comparison with the HAL and HAL+ LV-Ctrl groups (all $\mathrm{P}<0.05$; Fig. 6B). A TUNEL assay was also performed to detect the apoptotic cells in the tumor tissues. The results demonstrated that combined treatment with HAL + LV-H721 significantly enhanced cell apoptosis compared with that observed in the control, HAL and HAL + LV-Ctrl groups $(\mathrm{P}<0.01, \mathrm{P}<0.05$ and $\mathrm{P}<0.05$, respectively; Fig. $6 \mathrm{C}$ and $\mathrm{D})$. Collectively, these results indicated that HAL treatment may promote the microvascular growth. However, HIF-1 $\alpha$ knockout in tumor tissues significantly inhibited the tumor hypoxia-mediated increase in CD31 expression and the microvascular growth, while it promoted tumor cell apoptosis in vivo. These results further highlight the relevance of HIF-1 $\alpha$ inhibition in combination with HAL in the treatment of advanced, unresectable HCC.

\section{Discussion}

TAE, including TACE, is one of the most important treatment strategies for advanced HCC; however, these methods have various side effects. TAE has been suggested to aggravate the hypoxia condition of solid tumors and inevitably activate various pathways that promote cell invasion, tumor metastasis and angiogenesis $(27,28)$. Previously, Hanahan and Weinberg (29) proposed ten hallmarks of cancer and therapeutic targets for these hallmarks. In the present study, HIF-1 $\alpha$ was proposed as a potentially effective therapeutic knockout target of the hallmarks of HCC during TAE. The results demonstrated that $H I F-1 \alpha$ knockout in SMMC-7721 cells significantly suppressed cell invasiveness and migration, and induced cell apoptosis under $\mathrm{CoCl}_{2}$-simulated hypoxic conditions. Hepatic artery ligation (HAL) was used to mimic human transarterial chemoembolization in mice. Results showed that the combination method of HAL and Cas9-mediated genome editing exhibited an anti-tumor effect in an orthotopic HCC model, as well as prolonged the survival of tumor-bearing mice. The current preclinical study indicates that the combination of HAL and HIF-l $\alpha$ knockout may have a huge potential for further clinical applications. 
A

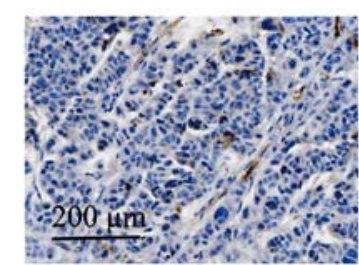

Ctrl

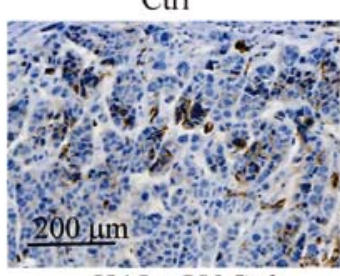

HAL+ LV-Ctrl

C

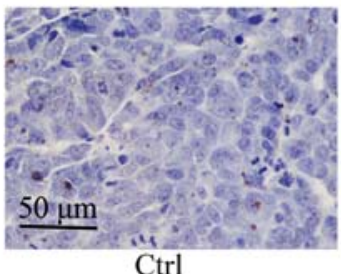

Ctrl

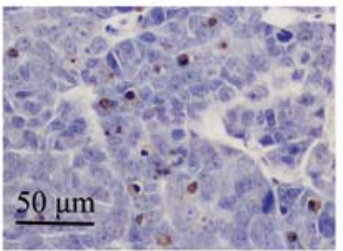

HAL+ LV-Ctrl

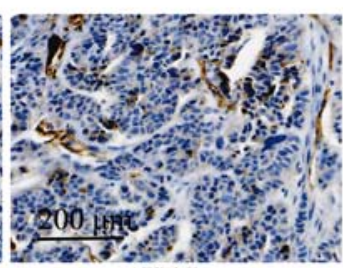

HAL

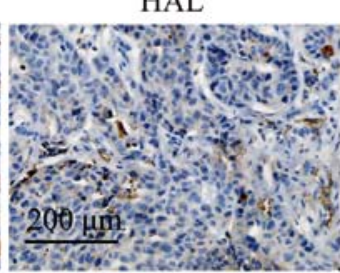

HAL+ LV-H721

B

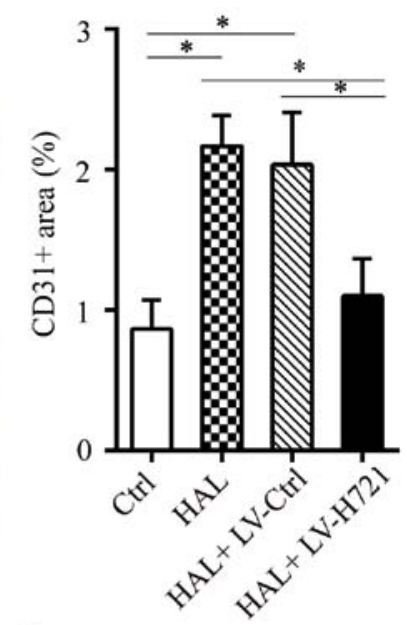

D
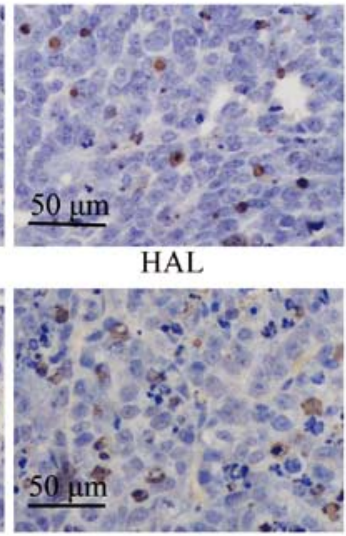

$\mathrm{HAL}+\mathrm{LV}-\mathrm{H} 721$

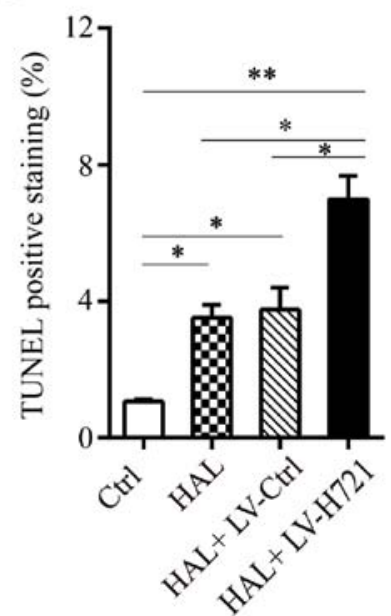

Figure 6. Immunohistochemical analysis of microvascular density and TUNEL assay in the mouse orthotopic tumor model. Tumor tissues were acquired at 20 days after the different treatments. (A) Monoclonal anti-CD31 antibody staining of the section to examine the microvascular density with $\mathrm{x} 20$ magnification, and (B) CD31-positive cells. Five sections were counted for each slide. (C) TUNEL assay was performed on the SMMC-7721-Fluc-induced orthotopic hepatocellular carcinoma model in mice with x20 magnification, and (D) the percentage of TUNEL-positive cells is presented. Values represent the mean \pm standard error of the mean, and are representative of four independent experiments. ${ }^{*} \mathrm{P}<0.05,{ }^{* *} \mathrm{P}<0.01$. HAL, hepatic artery ligation; Ctrl, control; LV, lentivirus.

Enhanced tumor invasion, distant metastasis and neovascularization subsequent to TAE treatment are the most severe complications observed (30). Furthermore, the development, progression, metastasis and recurrence of HCC are known to be closely associated with angiogenesis. HIF- $1 \alpha$ is the key regulator of angiogenesis under hypoxic conditions and a useful predictor of prognosis in patients with HCC. Thus, HIF-1 $\alpha$ is an ideal target for improving the therapeutic efficacy of TAE/TACE, and previous studies have reported that RNA interference targeting HIF-1 $\alpha$ resulted in an ameliorative efficacy compared with that observed in the TACE group $(31,32)$. In the present study, the lentiviral delivery (LV-H721) of the CRISPR/Cas9 protein and an $H I F-1 \alpha$-specific sgRNA resulted in highly efficient $H I F-1 \alpha$ modification (Fig. 2C), and the suppression of VEGF and MDR1 in SMMC-7721 liver tumor cells, indicating that $H I F-1 \alpha$ was efficiently disrupted by the CRISPR/Cas9 system (Fig. 2D and G). These findings are consistent with the observations of previous studies on HIF-1 $\alpha$, where HIF-1 $\alpha$ downregulation was reported to inhibit the expression levels of VEGF and MDR1 in cancer cells (17,33). Notably, LV-H721 infection led to HIF-1 $\alpha$ knockout in the SMMC-7721 xenograft tissues (Fig. 2A). In addition, $\mathrm{CoCl}_{2}$ was used to mimic a hypoxic tumor microenvironment in vitro (34), and the in vitro anti-tumor effect of the HIF-1 $\alpha$ knockout in the SMMC-7721 cells was exhibited by the impairment of the liver cancer cell migration and invasiveness capacities, particularly under hypoxic conditions (Fig. 3). Under hypoxic conditions, $H I F-1 \alpha$ knockout reduced cell proliferation and was accompanied by increased cell apoptosis in the SMMC-7721 cells (Fig. 4), indicating that combining the CRISPR/Cas9 system targeting $H I F-1 \alpha$ with TAE in the hypoxic tumor microenvironment may more efficient in HCC treatment. Notably, this combination therapy of CRISPR/Cas9-mediated $H I F-1 \alpha$ knockout and TAE (namely the HAL + LV-H721 treatment) conferred a more significant tumor suppressive effect and a prolonged survival time in the HCC-bearing mice (Fig. 5). Furthermore, the reduced expression of CD31 in the HAL + LV-H721 tumor tissues indicated that 
tumor angiogenesis was effectively inhibited by the $H I F-1 \alpha$ knockout (Fig. 6). Thus, HIF-1 $\alpha$, a key regulator of angiogenesis, cell migration and cell invasiveness capacity, may be an effect therapeutic knockout target during TAE in the treatment of HCC.

The emerging CRISPR/Cas9 system has several advantages and has rapidly changed the landscape of cancer biology (35). By simply combining the expression of CRISPR/Cas9 and sgRNAs, highly efficient tumor genome engineering was achieved. Relevant research studies have reported that CRISPR/Cas9 interventions targeting hepatitis $\mathrm{B}$ virus (HBV) cellular genes in cancer resulted in the cleavage of the HBV genome and viral clearance in a mouse model $(36,37)$. Nevertheless, the application of the lentiviral CRISPR/Cas9 system in clinical cases is limited by the lack of efficient delivery methods and the toxicity of the Cas9 nuclease (38). Notably, lentivirus infection and the CRISPR/Cas9 system mediating the knockout of a certain gene is permanent, and causes insertion inactivation of genes and off-target events. Therefore, the development of a delivery vector and a CRISPR/Cas9 system that mainly targets only the cancer cell genome is highly desirable. In the current study, SMMC-7721 cells were first infected with LV-H721 lentivirus and then used to establish an HCC mouse model. However, for the combination of TAE and the lentivirus-mediated CRISPR/Cas9 system, it may be better to inject an emulsion of materials that include the LV-H721 lentivirus into the HCC feeding arteries, thereby blocking the blood supply to the tumor. Furthermore, compared with the use of an intravenous systemic injection, a more efficient $H I F-1 \alpha$ gene knockout may be achieved by hepatic transarterial embolization with LV-H721 due to the close encounters between the lentiviruses, HCC tissues and a desirable $H I F-1 \alpha$ target. Thus, an extension of the current study could further utilize this combination strategy in rats. Thus far, it appears that using the lentivirus-mediated CRISPR/Cas9 system to correct an error in a certain human gene or to remove an alien gene may be more practical and achievable during TAE. Further studies are required to elucidate the application of the CRISPR/Cas9 system in treating human malignancies with a lentivirus vector.

In conclusion, the present study revealed that the CRISPR/Cas9-mediated $H I F-1 \alpha$ knockout enhanced the antitumor effect of TAE in HCC, suggesting that HIF-1 $\alpha$ may serve as a potential clinical knockout target, in combination with TAE/TACE, for the treatment of HCC.

\section{Acknowledgements}

We are grateful to Qingshuang Zou, Jianlong Kang and Shiyou Chen for their contributions to this project. We thank Jie Zhang, Wei Ma, Yang Li, Shang Chen and Weilin Lu for their animal management and technical supports.

\section{Funding}

This study was funded by the National Natural Science Foundation of Guangdong (grant no. 2015A030310409, 2017A030313846), and the Science and Technology Innovation Foundation of Shenzhen (grant no. JCYJ20160422152408705).

\section{Availability of data and materials}

All data generated or analyzed during this study are included in this published article.

\section{Authors' contributions}

LPL and SYB conceived and designed the study; QL and DA wrote the manuscript, carried out cellular and animal-associated experiments and performed statistical analyses; DF collected the clinical samples and analyzed the clinical information; ZW, YZ and ZYD assisted with the collection of clinical tumor samples, Transwell and TUNEL staining assay; DW and YL assisted with PCR, western blotting and packaging and purification of CRISPR/Cas9 lentiviruses; RL was involved in the conception of the study; QTY was responsible for cell culture and IHC staining. All authors read and approved the manuscript and agreed to be accountable for all aspects of the research in ensuring that the accuracy or integrity of any part of the work are appropriately investigated and resolved.

\section{Ethics approval and consent to participate}

The present study conformed to the Ethical Guidelines of the 2013 revision of the Declaration of Helsinki. All the HCC patients provided written informed consent for the use of clinical specimens for medical research. The studies using the human specimens and the mouse experiments were approved by the Ethics Committee of the Jinan University (Guangzhou, Guangdong, China). All the animal experiments were conducted with the standard guidelines for the care of animals, which were approved by the Welfare Committee of the Center of Experimental Animals (Jinan University, Guangzhou, Guangdong, China).

\section{Patient consent for publication}

All author consent to the publication of this work.

\section{Competing interests}

The authors declare that they have no competing interests.

\section{References}

1. Siegel RL, Miller KD and Jemal A: Cancer statistics, 2016. CA Cancer J Clin 66: 7-30, 2016.

2. Forner A, Llovet JM and Bruix J: Hepatocellular carcinoma. The Lancet 379: 1245-1255.

3. Omyla-Staszewska J and Deptala A: Effective therapeutic management of hepatocellular carcinoma-on the basis of a clinical case. Contemp Oncol 16: 60-63, 2012.

4. Song DS, Nam SW, Bae SH, Kim JD, Jang JW, Song MJ, Lee SW, Kim HY, Lee YJ, Chun HJ, et al: Outcome of transarterial chemoembolization-based multi-modal treatment in patients with unresectable hepatocellular carcinoma. World J Gastroenterol 21: 2395-2404, 2015.

5. Wang YX, De Baere T, Idee JM and Ballet S: Transcatheter embolization therapy in liver cancer: An update of clinical evidences. Chin J Cancer Res 27: 96-121, 2015.

6. Lo CM, Ngan H, Tso WK, Liu CL, Lam CM, Poon RT, Fan ST and Wong J: Randomized controlled trial of transarterial lipiodol chemoembolization for unresectable hepatocellular carcinoma. Hepatology 35: 1164-1171, 2002. 
7. Pecot CV, Calin GA, Coleman RL, Lopez-Berestein G and Sood AK: RNA interference in the clinic: Challenges and future directions. Nat Rev Cancer 11: 59-67, 2011.

8. Sharma P and Allison JP: The future of immune checkpoint therapy. Science 348: 56-61, 2015.

9. Liu Q, Yang Y, Tan X, Tao Z, Adah D, Yu S, Lu J, Zhao S, Qin L, Qin L and Chen X: Plasmodium parasite as an effective hepatocellular carcinoma antigen glypican-3 delivery vector. Oncotarget 8: 24785-24796, 2017.

10. Rosenberg SA and Restifo NP: Adoptive cell transfer as personalized immunotherapy for human cancer. Science 348: 62-68, 2015.

11. Doudna JA and Charpentier E: Genome editing. The new frontier of genome engineering with CRISPR-Cas9. Science 346: 1258096,2014

12. Cong L, Ran FA, Cox D, Lin S, Barretto R, Habib N, Hsu PD, Wu X, Jiang W, Marraffini LA and Zhang F: Multiplex genome engineering using CRISPR/Cas systems. Science 339: 819-823, 2013.

13. Eid A and Mahfouz MM: Genome editing: The road of CRISPR/Cas9 from bench to clinic. Exp Mol Med 48: e265, 2016.

14. Zucman-Rossi J, Villanueva A, Nault JC and Llovet JM: Genetic landscape and biomarkers of hepatocellular carcinoma. Gastroenterology 149: 1226-1239 e1224, 2015.

15. Favaro E, Lord S, Harris AL and Buffa FM: Gene expression and hypoxia in breast cancer. Genome Med 3: 1-12, 2011.

16. Unruh A, Ressel A, Mohamed HG, Johnson RS, Nadrowitz R, Richter E, Katschinski DM and Wenger RH: The hypoxia-inducible factor- 1 alpha is a negative factor for tumor therapy. Oncogene 22: 3213-3220, 2003.

17. Kang MJ, Jung SA, Jung JM, Kim SE, Jung HK, Kim TH, Shim KN, Yi SY, Yoo K and Moon IH: Associations between single nucleotide polymorphisms of $M M P 2, V E G F$, and $H I F 1 A$ genes and the risk of developing colorectal cancer. Anticancer Res 31: 575-584, 2011.

18. Yang SL, Liu LP, Jiang JX, Xiong ZF, He QJ and Wu C: The Correlation of Expression Levels of HIF-1 $\alpha$ and HIF-2 $\alpha$ in hepatocellular carcinoma with capsular invasion, portal vein tumor thrombi and patients' clinical outcome. Jpn J Clin Oncol 44 159-167, 2014

19. Chen M, Huang SL, Zhang XQ, Zhang B, Zhu H, Yang VW and Zou XP: Reversal effects of pantoprazole on multidrug resistance in human gastric adenocarcinoma cells by down-regulating the V-ATPases/mTOR/HIF-1 $\alpha /$ P-gp and MRP1 signaling pathway in vitro and in vivo. J Cell Biochem 113: 2474-2487, 2012.

20. Jia ZZ, Jiang GM and Feng YL: Serum HIF-1alpha and VEGF levels pre- and post-TACE in patients with primary liver cancer. Chin Med Sci J 26: 158-162, 2011.

21. Liu K, min XL, Peng J, Yang K, Yang L and Zhang XM: The Changes of HIF-1alpha and VEGF expression after TACE in patients with hepatocellular carcinoma. J Clin Med Res 8: 297-302, 2016.

22. Yu S, Yao Y, Xiao H, Li J, Liu Q, Yang Y, Adah D, Lu J, Zhao S, Qin L, et al: Simultaneous knockout of $C X C R 4$ and $C C R 5$ genes in $\mathrm{CD} 4^{+} \mathrm{T}$ cells via CRISPR/Cas9 confers resistance to both X4- and R5-tropic human immunodeficiency virus type 1 infection. Hum Gene Ther 29: 51-67, 2017.

23. Wang S, Zeng X, Liu Y, Liang C, Zhang H, Liu C, Du W and Zhang Z: Construction and characterization of a PDCD5 recombinant lentivirus vector and its expression in tumor cells. Oncol Rep 28: 91-98, 2012.
24. Lopez-Sanchez LM, Jimenez C, Valverde A, Hernandez V, Peñarando J, Martinez A,Lopez-Pedrera C, Muñoz-Castañeda JR, De la Haba-Rodríguez JR, Aranda E, et al: $\mathrm{CoCl}_{2}$, a mimic of hypoxia, induces formation of polyploid giant cells with stem characteristics in colon cancer. PLoS One 9: e99143, 2014.

25. Zhang YB, Wang X, Meister EA, Gong KR, Yan SC, Lu GW, Ji XM and Shao G: The effects of $\mathrm{CoCl}_{2}$ on HIF-1 $\alpha$ protein under experimental conditions of autoprogressive hypoxia using mouse models. Int J Mol Sci 15: 10999-11012, 2014.

26. Ma SH, Chen GG, Yip J and Lai PB: Therapeutic effect of alpha-fetoprotein promoter-mediated tBid and chemotherapeutic agents on orthotopic liver tumor in mice. Gene Ther 17: 905-912, 2010.

27. Ikeda M, Maeda S, Shibata J, Muta R, Ashihara H, Tanaka M, Fujiyama $\mathrm{S}$ and Tomita K: Transcatheter arterial chemotherapy with and without embolization in patients with hepatocellular carcinoma. Oncology 66: 24-31, 2004.

28. Soeda A, Park M, Lee D, Mintz A, Androutsellis-Theotokis A, McKay RD, Engh J, Iwama T, Kunisada T, Kassam AB, et al: Hypoxia promotes expansion of the CD133-positive glioma stem cells through activation of HIF-1alpha. Oncogene 28: 3949-3959, 2009.

29. Hanahan D and Weinberg RA: Hallmarks of cancer: The next generation. Cell 144: 646-674, 2011.

30. Liu K, min XL, Peng J, Yang K, Yang L and Zhang XM: The changes of HIF-1 $\alpha$ and VEGF expression after TACE in patients with hepatocellular carcinoma. J Clin Med Res 8: 297-302, 2016.

31. Chen CS, Zhao Q, Qian S, Li HL, Guo CY, Zhang W, Yan ZP, Liu R and Wang JH: Ultrasound-guided RNA interference targeting HIF-1 alpha improves the effects of transarterial chemoembolization in rat liver tumors. Onco Targets Ther 8: 3539-3548, 2015.

32. Chen C, Wang J, Liu R and Qian S: RNA interference of hypoxia-inducible factor-1 alpha improves the effects of transcatheter arterial embolization in rat liver tumors. Tumour Biol 33: 1095-1103, 2012.

33. Shan JZ, Xuan YY,Zhang Q and Huang JJ: Ursolic acid sensitized colon cancer cells to chemotherapy under hypoxia by inhibiting MDR1 through HIF-1 $\alpha$. J Zhejiang Univ Sci B 17: 672-682, 2016.

34. Wang M, Zhao X, Zhu D, Liu T, Liang X, Liu F, Zhang Y, Dong X and Sun B: HIF-1 $\alpha$ promoted vasculogenic mimicry formation in hepatocellular carcinoma through LOXL2 up-regulation in hypoxic tumor microenvironment. J Exp Clin Cancer Res 36: 60, 2017.

35. Sanchez-Rivera FJ and Jacks T: Applications of the CRISPR-Cas9 system in cancer biology. Nat Rev Cancer 15: 387-395, 2015.

36. Zhen S, Hua L, Liu YH, Gao LC, Fu J, Wan DY, Dong LH, Song HF and Gao X: Harnessing the clustered regularly interspaced short palindromic repeat (CRISPR)/CRISPR-associated Cas9 system to disrupt the hepatitis B virus. Gene Therapy 22: 404-412, 2015

37. Seeger C and Ji AS: Complete spectrum of CRISPR/Cas9-induced mutations on HBV cccDNA. Mol Ther 24: 1258-1266, 2016.

38. White MK and Kamel K: CRISPR/Cas9 and cancer targets: Future possibilities and present challenges. Oncotarget 7: 12305-12317, 2016.

This work is licensed under a Creative Commons Attribution-NonCommercial-NoDerivatives 4.0 International (CC BY-NC-ND 4.0) License. 